\title{
Correction to: Modelling Epileptic Activity in Hippocampal CA3
}

\author{
Sanjay M. and Srinivasa B. Krothapalli
}

\section{Correction to:}

Chapter 22 in: V. Cutsuridis et al. (eds.), Hippocampal Microcircuits, Springer Series in Computational Neuroscience, https://doi.org/10.1007/978-3-319-99103-0_22

In the original version of this chapter the corresponding author Srinivasa B. Krothapalli's affiliation was incorrectly mentioned as Department of Electrical Engineering, National Institute of Technology Calicut, Kattangal, Kerala, India. The affiliation is now corrected as 'Neurophysiology Unit, Department of Neurological Sciences, Christian Medical College, Vellore, India'. The same has been updated in Contributors list in the FM.

The updated version of this chapter can be found at https://doi.org/10.1007/978-3-319-99103-0_22 